\title{
Editorial
}

\section{Emerging Need of New Medical Journals}

Medical advances will keep on putting upward pressure on the need for new medical journals (to find a space for publications). Dissemination of data from clinical trials needs to be on urgent basis for the benefit of millions of people. Authors themselves want to publish their work at earliest. Our journal must guarantee this after a rigorous peer-review ${ }^{1}$ Unfortunately in Pakistan many publication have been uncontrolled, unregulated and with erratic results. In view of above, to maintain the standard, many medical journals of Pakistan have been de-recognized or downgraded recently. Many doctors were contributing articles to the journals only to improve their curriculum vitae for promotions or support grant proposals. New journals I am sure must be carrying results from strictly controlled process and would be useful for medical professionals and patients alike. Articles won't be meant to secure tenure and further grants or by the need of pharmaceutical industry to promote their products. ${ }^{2}$ This positive trend has created a chance for new high quality journals recognition. Hopefully new journals will come up to the standards to be of any use. In Pakistan the medical education Programs till now assumed that training was not needed for written medical communications. Recently this subject has been taken up seriously at many levels. Medical students and house officers will be encouraged to participate in research work and get their articles published. They would be provided with experienced mentors with a record of good publications. ${ }^{3}$ Another important issue getting the article published in a reputable journal is the cost. Moreover cost of publishing in open-access journals bears little correlation to their impact. Once recognized we will try to keep our cost of publishing to the minimum. ${ }^{3}$ Common shortcomings of the journal publications are insufficient quality of the information provided and outcome reporting bias. This can be cover by the reporting guidelines and peer review by experts. Bias can be avoided by adopting new ways of data presentation in electronic databases and the potential use of anonymized individual patient data. ${ }^{4,5} \mathrm{We}$ will try to give equal opportunities to ladies to serve as peer reviewers and editorial writers, in contrast to previous practices. ${ }^{4}$ Our editors have to focus on professionalism to establish transparent and ethical working practice. Medical writing encompasses a wide field of diverse forms of written communication. Useful material has to be distinguished from ordinary messages. Aziz Fatimah Medical Journal must be considered a sacred space meant for intellectuals willing to share their honest research for the betterment of society. I hope and I pray that our journal will come up to the mark of highest standards at least in Pakistan.

\section{References}

1.Pozzilli, P. Fast publication, a must for a journal. Diabetes Metab Res Rev, 2018;34(1). doi: 10.1002/dmrr.2978.34.

2.Matheson A. Canself-regulation deliver an ethical commercial literature? Acritical reading of the "Good Publication Practice"(GPP3) guide lines for industry-financed medical journal articles.2019; 26(2):85-107. doi: 10.1080/08989621.

3. Yuen J, Muquit S, Whitfield PC. Correlation between cost of publication and journal Impact. Comprehensive crosssectional study of exclusively open- access surgical journals. J Surg Educ. 2019; 76(1):107-119. doi: 10.1016/j.jsurg.2018.06.029.

4.Williams WA, Garvey KL. The Role of Gender in Publication in the Journal of Pediatrics 2015-2016: Equal Reviews, unequal opportunities. J Pediatr. 2018; 200 :254-260.e1. doi: 10.1016/j.jpeds.2018.06.059. Review

5.Wieseler B. Beyond journal publications- A new format for the publication of clinical trials. Z Evid Fortbild Qual Gesundhwes. 2017 Feb;120:3-8. doi: 10.1016/j.zefq.2016.11.003.

\section{Chief Editor}

Maj. Gen (R) Prof. Dr. Hamid Shafiq HI (M)

Principal

Aziz Fatimah Medical and Dental College,Faisalabad. 